\section{Properties of the Non-Calcareous Material in the Shell of Anodonta cygnea}

THE shell in the Lamellibranchia consists of a number of distinct layers which show a fundamental similarity in structure in related regions of valve and ligament ${ }^{1}$. In Anodonta, all parts of the shell, except the periostracum and the fusion and outer layers of the ligament, are calcified and contain a non-calcareous matrix, termed conchiolin, which in sections possesses characteristic staining properties. Conchiolin of the inner layers of valve and ligament stains typically with basic dyes, outer layer conchiolin predominantly with acid dyes, and fully-formed periostracum and fusion layer usually remain uncoloured.

A number of histochemical tests have been carried out on the shell conchiolin which indicate that it consists mainly of protein (ninhydrin, xanthoproteic, arginine ${ }^{2}$ and Millon tests), although lipoid material (sudan black stain) and possibly some polysaccharide (periodic acid-Schiff test ${ }^{3}$ ) may be present. The detailed results of these tests indicate that there is a similarity in the properties of corresponding layers of valve and ligament and also that, as reported by Trueman in Tellina tenuis, the conchiolin of the inner layers of valve and ligament differs in composition from that in the rest of the shell. The chitosan-iodine test for chitin ${ }^{5}$ gives a slightly positive reaction with Anodonta conchiolin. The periostracum, fusion and outer layers give a more strongly positive reaction to the argentaffine test $^{6}$ than the inner layers, suggesting the presence of quinone-tanned proteins. Sections treated with a series of reagents devised by Brown ${ }^{z}$ to determine the types of linkages in structural proteins dissolve almost completely only in the sodium hypochlorite solution, providing further evidence for tanning having taken place.

The amino-acid content of the conchiolin protein has been further investigated by paper chromatography. The shell was treated in four parts, namely,

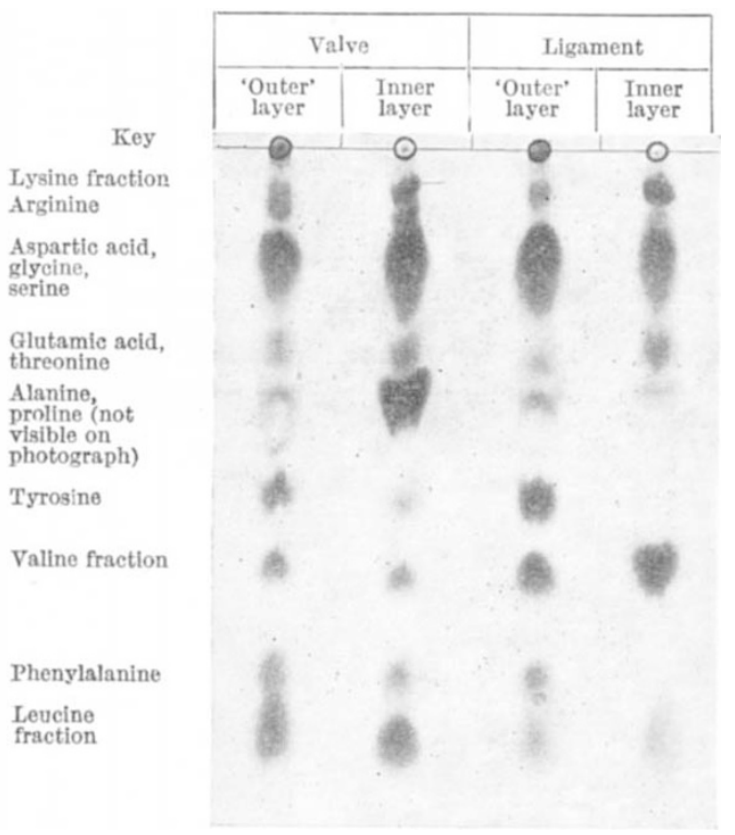

Fig. 1. A chromatogram of hydrolysates of the shell conchiolin of Anodonta cygnea run on Whatman No. 1 flter-paper using butanol/ acetic acid/water as solvent 'outer' layer valve (including periostracum as well as true outer layer), inner layer valve, 'outer' layer ligament (including fusion layer as well as true outer layer) and inner layer ligament. Acid hydrolysates of equal quantities of dried conchiolin from each region were run simultaneously on paper chromatograms, using phenol/water and butanol/acetic acid/water as solvents, and developed with ninhydrin. The results reveal that although the general pattern of the amino-acids produced from each hydrolysate is somewhat similar, there are $\operatorname{som} \theta$ marked differences in concentration (Fig. 1). Tyrosine is relatively more abundant in the 'outer' layers of both valve and ligament and phenylalanine is more highly concentrated in the 'outer' layer of the ligament than in the inner. Arginine and certain other amino-acids, however, show relatively higher concentrations in both inner layers. These results, and, in particular, the striking similarity in amino-acid content of the 'outer' layers of valve and ligament (Fig. 1), agree in general with the responses observed to the histochemical tests for amino-acid groups.

This work, which will be published in full later, appears to provide further evidence for the homology established on morphological grounds between the layers of valve and ligament. Moreover, the difference in composition between the conchiolin of the inner layers of valve and ligament and that in the rest of the shell, as indicated by its staining properties in sections, is reflected by the results of the histochemical tests and chromatographic analyses carried out.

I wish to thank Prof. P. G. 'Espinasse and Mr. E. R. Trueman for help and guidance and the authorities of the University of Hull for the research scholarship which has made this work possible.

Department of Zoology

G. E. BeEDham

University, Hull. June 29.

2 Owen, G., Trueman, E. R., and Yonge, C. M., Nature, 171, 73 (1953).

2 Baker, J. R., Quart. J. Micr. Sci., 88, 115 (1947).

s Hotchkiss, R. D., Arch. Biochem., 16, 131 (1948).

- Trueman, E. R., Proc. Zool. Soc., Lond., 119, 717 (1949).

'Campbell, F. L., Ann. Ent. Soc. Amer., 22, 401 (1929).

- Lison, L., "Histochimie animale" (Paris, 1936).

${ }^{7}$ Brown, O. H., Quart. J. Micr. Sci, 91, 331 (1950).

\section{Examination of Soil Micro-organisms in their Natural Environment}

Present information on the distribution and growth of micro-organisms in the soil has been obtained almost entirely by plating dilute soil suspensions on to nutrient media, the Rossi-Cholodny ${ }^{1}$ buried slide technique, Jones and Mollison's ${ }^{2}$ soil suspension preparations and similar indirect methods. Kubiena ${ }^{3}$ has developed methods of examining soil organisms in situ using reflected light, but his observations are necessarily confined to soil surfaces. So far as we are aware, the technique of preparing thin sections of soils and non-coherent rocks for microscopical examination by transmitted light has not previously been applied to the study of soil microorganisms in their natural environment.

In the present method, standard soil sampling and rock slicing techniques have been modified with the object of keeping the soil and soil micro-organisms as nearly as possible in their natural state. This involves keeping the stresses acting on the sample small and the temperature low. Small soil samples are taken in a polythene tube fitted with a detach- 